\title{
Surgical approach to repair of ruptured chordae tendineae causing tricuspid regurgitation
}

\author{
Vincent Chan, MD, ${ }^{\mathrm{a}}$ Dominique Grisoli, MD, ${ }^{\mathrm{a}}$ Marc Ruel, MD, MPH, ${ }^{\mathrm{a}, \mathrm{b}}$ John Veinot, MD, ${ }^{\mathrm{c}}$ and Thierry Mesana, MD, PhD, ${ }^{\mathrm{a}}$ \\ Ottawa, Ontario, Canada
}

Tricuspid regurgitation (TR) secondary to papillary muscle rupture is an uncommon surgical problem. We present 2 cases and offer an approach to surgical repair.

\section{CLINICAL SUMMARY \\ Case 1}

An otherwise healthy 53-year-old man was referred to cardiac surgery for assessment of acute TR after a motor vehicle collision 6 months previously. Severe TR was noted on the patient's initial echocardiogram, but given his multiple injuries no attempt was made for immediate surgical repair. Progressive dilation of the right ventricle developed during the following several months, and repeat echocardiography revealed progressive dilation of his right ventricle. The patient was therefore brought to the operating room for elective tricuspid valve repair.

In the operating room, the patient was found to have an isolated flail of the anterior tricuspid leaflet secondary to ruptured chordae (Figure 1, $A$ ). The tricuspid valve was repaired with a combination of bicuspidization (Figure 1, B), edge-toedge repair (Figure 1,C), and ring annuloplasty (Figure 1, $D)$. Intraoperative echocardiography revealed a post-repair orifice area of $2.6 \mathrm{~cm}^{2}$.

The patient had an uneventful postoperative course. One month after the operation, the patient remained asymptomatic and follow-up echocardiography revealed trace TR.

\section{Case 2}

A 60-year-old man with known coronary artery disease presented to cardiac surgery with a 6-month history of progressive dyspnea. Echocardiography confirmed severe TR with bileaflet flail and moderate right ventricle dilation. The patient was brought to the operating room for tricuspid valve repair and concomitant coronary artery bypass grafting.

In the operating room, the anterior and posterior tricuspid leaflets were found to be torn from their respective papillary muscles (Figure 2, A). The posterior leaflet was resected, and the septal leaflet chordae were transferred to the posteromedial aspect of the anterior leaflet with interrupted 5-0 Prolene

From the Division of Cardiac Surgery ${ }^{\mathrm{a}}$ and Departments of Epidemiology ${ }^{\mathrm{b}}$ and Pathology, ${ }^{\mathrm{c}}$ University of Ottawa, Ottawa, Ontario, Canada.

Received for publication March 6, 2008; accepted for publication March 17, 2008.

Address for reprints: Thierry Mesana, MD, PhD, University of Ottawa Heart Institute,

3402-40 Ruskin Street, Ottawa, Ontario, Canada, K1Y 4W7 (E-mail: tmesana@

ottawaheart.ca).

J Thorac Cardiovasc Surg 2009;137:e30-2

$0022-5223 / \$ 36.00$

Copyright (c) 2009 by The American Association for Thoracic Surgery doi: $10.1016 /$ j.jtcvs. 2008.03 .020 suture (Figure 2, $B$ ). The annulus was then reconstructed by plicating the resultant defect, caused by resection of the posterior leaflet, with pledgeted 3-0 Prolene suture and interrupted 5-0 Prolene suture (Figure 2, $C$ and $D$ ). The annulus was then measured at $28 \mathrm{~mm}$ with a Hegar sizer; therefore, no annuloplasty ring was implanted. The patient also received concomitant coronary bypass grafting. Post-repair echocardiography revealed a tricuspid orifice area of $2.8 \mathrm{~cm}^{2}$.

The patient had an uneventful postoperative course. Three months after surgery, the patient remained asymptomatic and repeat transthoracic echocardiography revealed 1+ TR.

\section{COMMENT}

Although described in the pediatric population and in patients after blunt trauma, severe TR secondary to ruptured chordae remains a rare and complex surgical problem. ${ }^{1,2}$ On the basis of the above cases, we propose 2 options for surgical TR repair.

The mechanism of TR in case 1 was the result of torn chordae from the anterior papillary muscle, thereby causing flail of the anterior leaflet. The posterior and septal leaflets, in addition to their respective chords and papillary muscles, were normal. The flail anterior leaflet could therefore be supported to the normal septal leaflet via an edge-to-edge repair (Figure 1,C) after bicuspidization (Figure 1,B). An annuloplasty ring was implanted to provide structural support because this patient was noted to have right ventricular dilation (Figure 1,D).

In case 2, anterior and posterior tricuspid leaflets were flail secondary to torn chordae and totally unsupported (Figure 2, $A)$. An edge-to-edge repair was not feasible in this scenario given that there remained no normal chordae from either prolapsing leaflet to provide structural support. The septal leaflet, however, was found to have proper functioning chordae tendineae. Therefore, after posterior leaflet resection, the septal chords were transferred medially to the anterior leaflet (Figure 2, B).

Few reports have described the surgical management of TR caused by torn chordae tendineae. In the setting of isolated traumatic papillary muscle rupture, the edge-to-edge technique has been described as a means of supporting a flail tricuspid leaflet. ${ }^{3}$ Neochordae and papillary muscle reinsertion have also been described. ${ }^{4}$

However, an edge-to-edge technique may be insufficient in the setting of bileaflet or trileaflet flail. In such situation, the flip-over technique involved the portion of the septal leaflet adjacent to the posterior-septal commissure without jeopardizing atrioventricular node function. The flip-over 

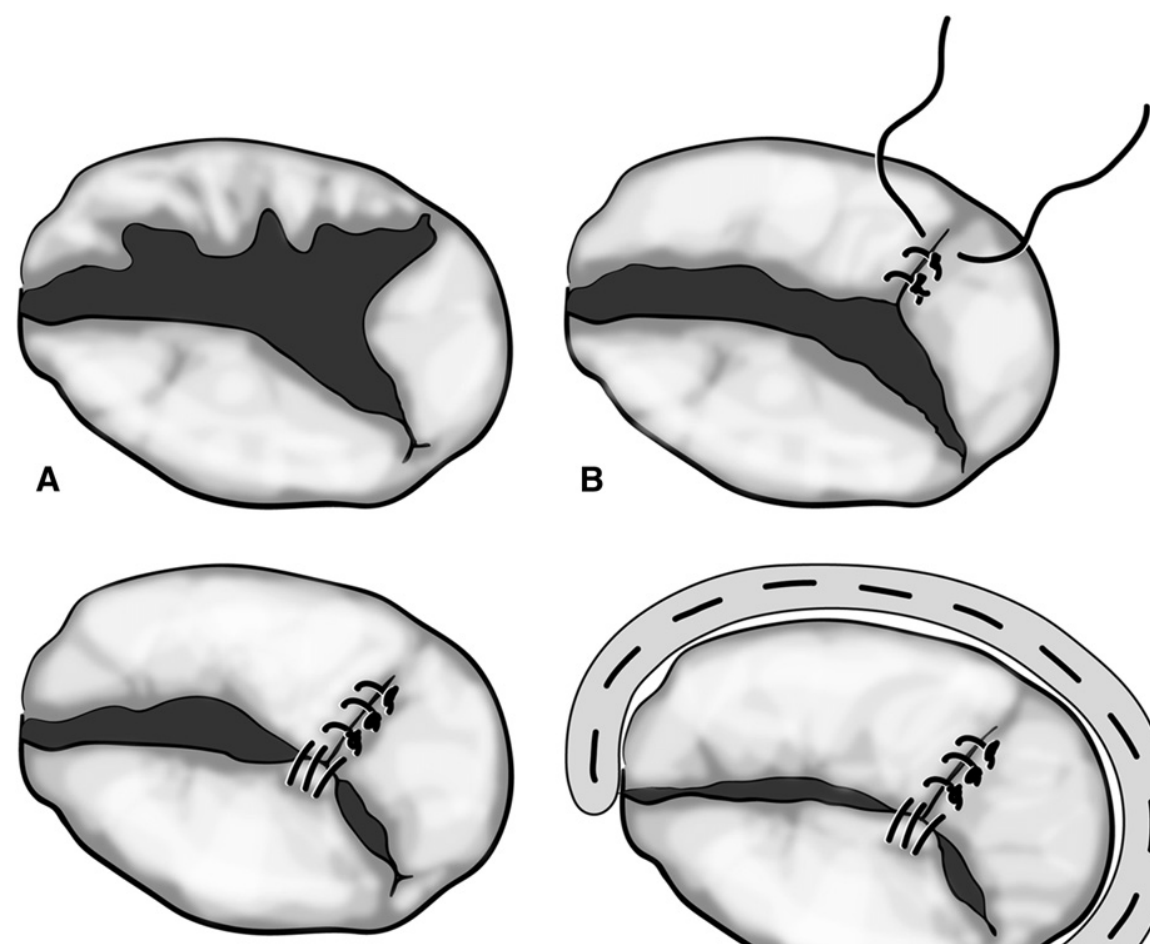

C

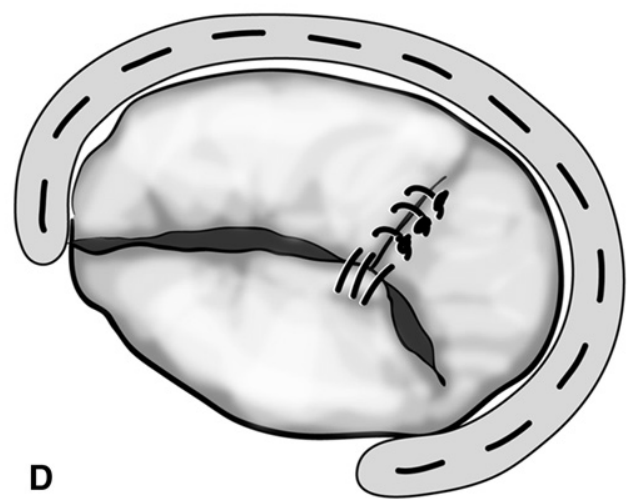

FIGURE 1. Repair of isolated anterior leaflet prolapse secondary to ruptured chordae tendineae. A, Anterior leaflet prolapse. B, Anterior and posterior tricuspid leaflets were sutured together with 5-0 Prolene suture. C, Edge-to-edge repair of anteroposterior leaflet to septal leaflet using 5-0 Prolene suture. D, Insertion of annuloplasty ring.

A
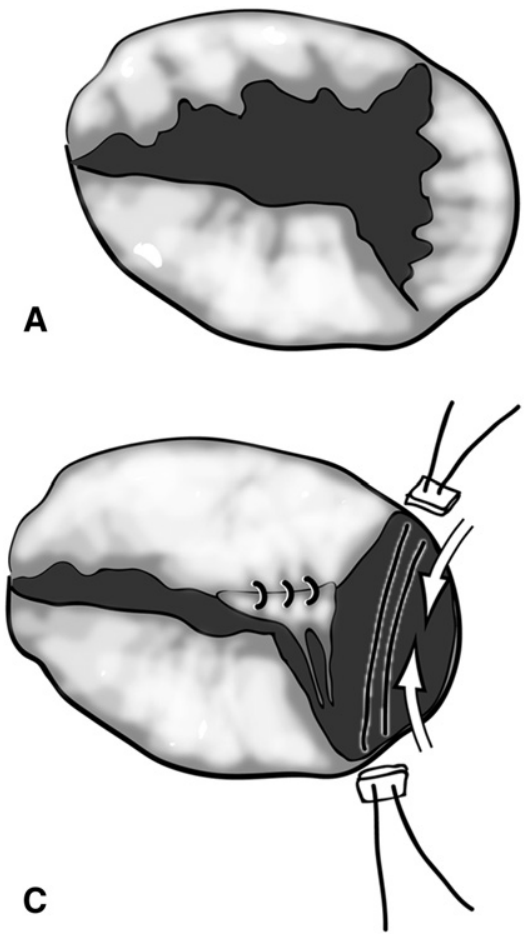
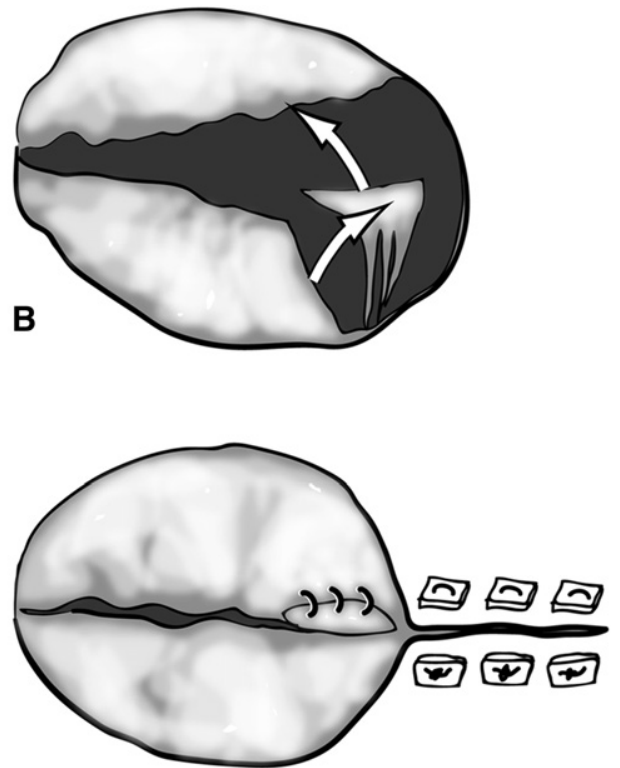

D

FIGURE 2. Repair of bileaflet prolapse secondary to ruptured chordae tendineae. A, Anterior and posterior tricuspid leaflet prolapse. B, Posterior leaflet resection with transfer of septal chordae to the anterior leaflet. C and D, Plication of annular defect with pledgeted 3-0 Prolene suture and interrupted 5-0 Prolene suture. 
with a lateral transfer toward the medial section of the anterior leaflet was achieved easily and without tension. This technique could also be applied to a more posterior segment of the anterior leaflet. To our knowledge, the surgical repair of bileaflet flail of the tricuspid valve has not been described. Common techniques for mitral valve repair, such as flip-over and edge-to-edge, are similarly applicable and successful in tricuspid valve repair as an alternative to tricuspid valve replacement.

\section{References}

1. Boon R, Hazekamp M, Hoohenkerk G, Rijlaarsdam M, Schoof P, Koolbergen D, et al. Artificial chordae for pediatric mitral and tricuspid valve repair. Eur J Cardiothorac Surg. 2007;32:143-8. Epub 2007 May 2.

2. Turkoz R, Gulcan O, Atalay H, Uguz E. Surgical repair of tricuspid valve regurgitation caused by blunt thoracic trauma. J Trauma. 2007;63:E7-9.

3. Kalangos A, Baldovinos A, Sezerman O, Faidutti B. Tricuspid valve repair by septal of posterior leaflet transposition. Ann Thorac Surg. 1995;60:1807-9.

4. Maisano F, Lorusso R, Sandrelli L, Torracca L, Coletti G, La Canna G, et al. Valve repair for traumatic tricuspid regurgitation. Eur J Cardiothorac Surg. 1996;10: 867-73.

\section{Is subtotal resection of a right ventricular fibroma a valid surgical option?}

Roland Henaine, MD, Emilie Adam, MD, Kasra Azarnoush, MD, N. Yashimura, MD, PhD, M. Cannesson, MD, A. Millon, MD,

F. Lachhab, MD, and Jean Ninet, MD, PhD, Lyon, France

We describe the case of a 40-year old woman with a right ventricular (RV) fibroma discovered after a syncopal episode, subtotal surgical resection was performed. Two years follow-up confirmed lesion stability.

\section{CLINICAL SUMMARY}

We describe the case of a 40-year old woman with a right ventricular (RV) fibroma discovered after a syncopal episode. The patient presented for a diagnostic workup after falling down during normal daily activity. The results of transthoracic echocardiography were normal. Sleep monitoring was then performed, and we concluded that the patient had narcolepsy disturbance. However, transesophageal echocardiographic analysis revealed a thickening of the intraventricular septum, bulging into the RV. Magnetic resonance imaging (MRI; Figure 1, $A$ ) showed a hypodense mass. Tumor markers were all within the normal range.

The result of a transvenous RV biopsy was normal. Thus it was decided to perform a surgical exploration through a median sternotomy. The pericardial cavity was free of ad-

From the Department of Cardiac Surgery C, Cardiologic Hospital Louis Pradel, Lyon, France.

Received for publication May 6, 2008; accepted for publication May 25, 2008.

Address for reprints: Roland Henaine, MD, Department of Cardiac Surgery C, Cardiologic Hospital Louis Pradel, Avenue du Doyen Lépine, 69394 Lyon, France

(E-mail: roland.henaine@chu-lyon.fr).

J Thorac Cardiovasc Surg 2009;137:e32-4

$0022-5223 / \$ 36.00$

Copyright (c) 2009 by The American Association for Thoracic Surgery doi:10.1016/j.jtcvs.2008.05.062

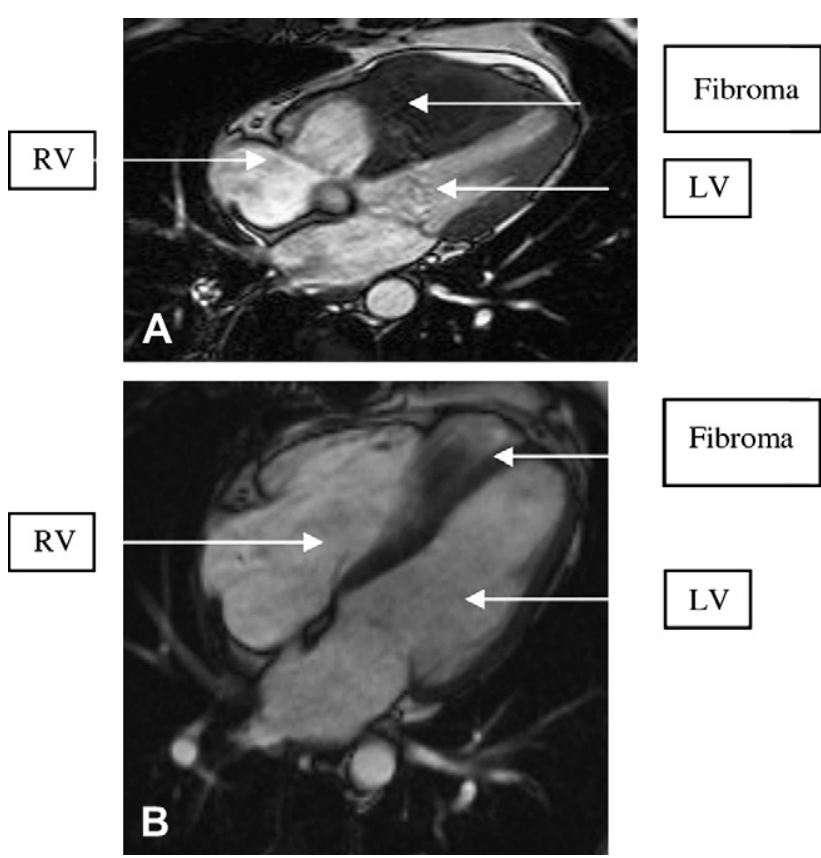

FIGURE 1. A, Preoperative magnetic resonance image: cross-section showing right interventricular fibroma from the interventricular septum. The magnetic resonance image shows a hypodense mass measuring $6 \times$ $4 \mathrm{~cm}$ located in the right ventricle, filling in all of the median and apical parts of the ventricle and spreading up to the pulmonary infundibulum close to the pulmonary valve which was widely open. Septal extension was difficult to visualizes, but the anterior pericardium seemed to be infiltrated. A pericardial effusion was also present. B, Postoperative magnetic resonance image at 2 years. $R V$, Right ventricle; $L V$, Left ventricle. 